APRESENTAÇÃO

\title{
HISTÓRIA E CULTURAS INDÍGENAS NA EDUCAÇÃO: ETNICIDADE, DIFERENÇA E OS 10 ANOS DA LEI No 11.645/2008
}

\author{
Danielle Bastos Lopes ${ }^{1}$ (D) \\ José Ribamar Bessa Freire ${ }^{1,2}$ (D)
}

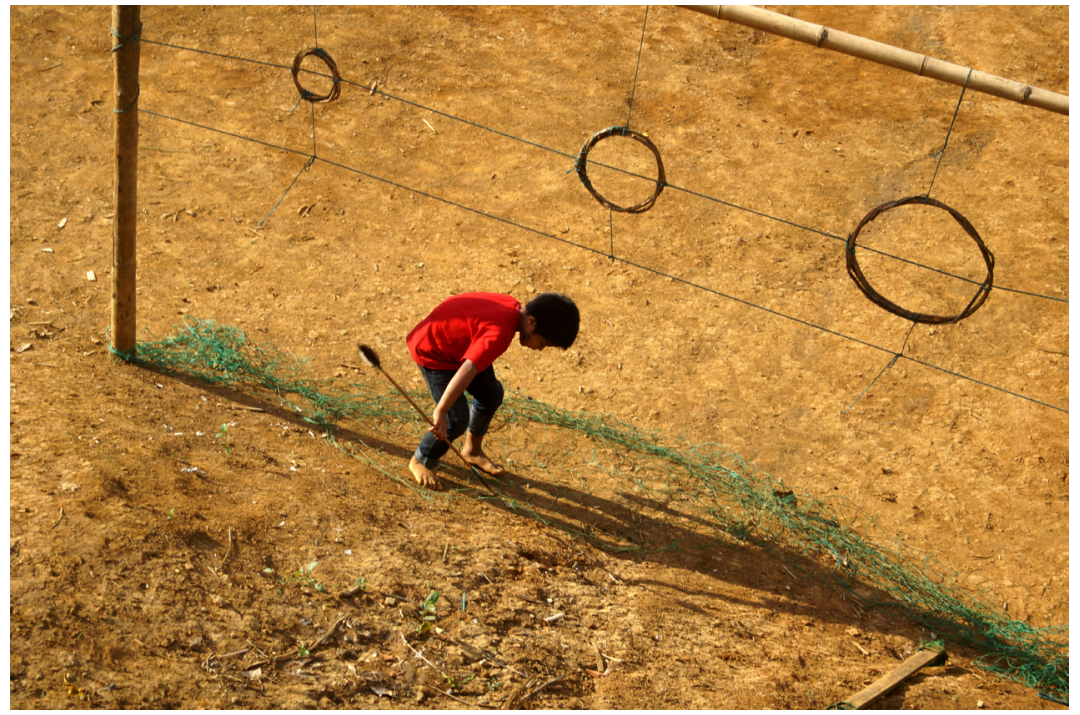

${ }^{1}$ Universidade do Estado do Rio de Janeiro - Rio de Janeiro (RJ), Brasil.

E-mails: daniellebastoslopes@hotmail.com; bessa_18@hotmail.com

${ }^{2}$ Universidade Federal do Estado do Rio de Janeiro - Rio de Janeiro (RJ), Brasil.

DOI: 10.1590/CC0101-32622019219557 


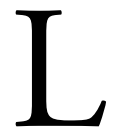

evamos 20 exemplares do livro paradidático Aldeamentos Indígenas do Rio de Janeiro à aldeia Sapukai, Angra dos Reis (RJ), em 1998, para ser utilizado na escola Kyringue Yvoty. O professor Algemiro Poty recebeu, agradeceu, folheou e esclareceu que os Guarani já conheciam o seu conteúdo. Com um leve tom de ironia, recomendou que o livro fosse distribuído às escolas não indígenas, dos juruá, uma vez que as escolas dos brancos "não ensinam aos alunos quem somos nós, nem mostram a importância dos índios para o Brasil. Por que as crianças brasileiras não conhecem os índios se na nossa escola aprendemos sobre quem é diferente de nós?" (FREIRE, 2001, p. 1). O fato ocorreu dez anos antes da Lei no 11.645/2008 (BRASIL, 2004; 2008). Seguimos sua recomendação. Levamos para as escolas não indígenas o livro que a EdUERJ editou em 1997 e reeditou mais de uma década seguinte (FREIRE; MALHEIROS, 2009).

A questáo é como ensinar o que pouco ou eurocentricamente se conhece. A obrigatoriedade do ensino indígena, extensiva à obrigatoriedade do ensino de história e culturas africanas na educação básica, foi um choque para o corpo acadêmico e escolar quando ambas emergiram no cenário brasileiro (BASTOS LOPES, 2013; 2017; BENITES, 2012; GRUPIONI, 2013; FREIRE, 2014). Mundos e sistemas culturais complexos foram submetidos a pesquisadores, externando certo colonialismo (ESCOBAR, 2014) e falta de familiaridade com o objeto quando a Lei foi aprovada.

As reformas curriculares dos anos 1990 aprovaram a obrigatoriedade do ensino indígena e africano, abrindo espaço para um ensino culturalmente híbrido, emergente e múltiplo. No entanto, as aprovaçóes e novas diretrizes não foram capazes de superar as dificuldades encontradas nas universidades ao oferecer cadeiras com disciplinas específicas em contexto simbólico e étnico predominantemente ocidental.

Um expressivo número de cursos de formação continuada e materiais pedagógicos foram, nesses esforços, reunidos em articulação com instituições acadêmicas latino-americanas (CORTÉS; APODACA, 2016; MELIÀ, 2010; MUÑOZ, 2010; CEPAL, 2018). Um mergulho em literaturas e fontes históricas contextualizam, nas últimas décadas, tentativas de implementação do ensino sobre indígenas. Passados dez 
anos, este dossiê tem o objetivo, portanto, de explorar a história e o ensino sobre culturas amerindias, investigando mudanças e os atuais reveses políticos dos quais o campo tem sido objeto. Assim, chegamos ao ponto central deste volume dos Cadernos CEDES: explorar limites e possibilidades em um cenário que tem discutido, por exemplo, configurar uma Base Nacional Comum Curricular (BNCC) e extinguir diretamente o debate étnico-racial dos currículos (MACEDO, 2016; PEREIRA; OLIVEIRA, 2014). Esta edição traz artigos de docentes e pesquisadores indígenas para tanto.

Danielle Bastos Lopes, ao abrir o dossiê, analisa experiências gerais e localizadas sobre a Lei no $11.645 / 2008$ nas escolas da rede pública do Rio de Janeiro. A autora pesquisa a ocidentalização de culturas indígenas no ensino. Entender o conflito, a sedução e os estranhamentos quando mundos indígenas são apresentados a crianças em idade escolar assume um dos pontos centrais do artigo.

José Bessa Freire, coordenador do PROÍNDIO-UERJ, e Ana Paula da Silva, membro do mesmo programa, investigam, dez anos depois, a recepção dos materiais didáticos produzidos em parceria com o Ministério de Educação (MEC) para ser utilizado em escolas públicas indígenas e não indígenas. Investigam a impressão do público na recepção das exposiçóes museais e os produtos criados pelo PROÍNDIO-UERJ, apresentando a contribuição do programa à Lei no $11.645 / 2008$.

Passando à atuação dos movimentos indígenas e ao debate intercultural, os pesquisadores Francisca Navantino (Chiquinha Paresi) e Edson de Andrade (Edson Krenak) narram experiências como pesquisadores e autores ameríndios. Chiquinha Paresi investiga a implementação da obrigatoriedade da Lei no 11.645/2008 nas Secretarias de Educação do estado e universidades do Mato Grosso.

Ao defender a presença dos acadêmicos indígenas no ensino, no Poder Judiciário e demais esferas políticas, Edson Krenak debruça-se sobre como o movimento social abrange uma múltipla teia de relaçóes entre indígenas e não indígenas, narrando suas experiências como parte do movimento social criado pela caravana Mekukradjá, um projeto para difundir a literatura e os conhecimentos ameríndios nas escolas. 
Ana Paula da Silva, com base nas trocas e saberes tradicionais das sociedades Tupi do período seiscentista, investiga o modo de ser, comer e ensinar na temporalidade jesuítica. A autora explora categorias classificatórias a respeito de plantas, objetos e animais, o que permite discutir parte do sistema taxonômico e o modo como os falantes Tupinambá conheciam e transmitiam seus ensinamentos.

No contexto universitário, Adir Casaro Nascimento, Carlos Vieira e Beatriz Landa focalizam aspectos do curso de formação de professores indígenas no estado do Mato Grosso do Sul. O artigo exalta a presença dos acadêmicos indígenas no âmbito institucional e suas contribuiçóes à Lei no 11.645/2008. Os depoimentos de ameríndios e não indígenas evidenciam as fissuras, as produçóes e as reelaboraçóes produzidas nos locais de tensão acadêmica.

Héctor Muñoz Cruz mapeia um panorama latinoamericano da representação indígena no campo sociolinguístico, analisando como as línguas nativas são representadas nos círculos de socialização linguística, incluindo o campo pedagógico e o político como contextos relevantes de representação.

O dossiê concentra, portanto, os assuntos ativos do campo da Educação e Etnologia.

Estudos recentes apontam o aumento de pesquisas evidenciando a agenda intercultural indígena na América Latina (CORTÉS; APODACA, 2016; MELIÀ, 2010; ROCKWELL, 2015). Explorar tais limites foi o que levou os autores deste volume a vasculhar em arquivos, manuscritos e narrativas outras. Esperamos, dessa forma, que o trabalho possa contribuir com a pergunta inicial feita pelo professor Guarani, estimulando novas reflexões e estranhamentos a pesquisadores indígenas e não indígenas.

\section{REFERÊNCIAS}

BASTOS LOPES, D. A presença do invisível em escolas indígenas: escolarização, diferença e cosmologia entre os povos Mbyá (Guarani) do Rio de Janeiro. Cadernos Cimeac, Uberaba, v. 7, n. 2, p. 103-119, 2017. https://doi. org/10.18554/cimeac.v7i2.2089 
BASTOS LOPES, D. E todo dia era dia de índio: a representação dos povos indígenas nos currículos escolares do Rio de Janeiro. Revista Poiésis, Santa Catarina, v. 7, n. 11, p. 96-113, 2013. http://dx.doi.org/10.19177/prppge. v7e11201396-112

BENITES, T. A escola na ótica dos Avá Kaiowá: impactos e interpretações indígenas. Rio de Janeiro: Contracapa, 2012.

BRASIL. Diretrizes Curriculares Nacionais para a Educação das Relaçôes Étnico Raciais e para o Ensino da História e Cultura Afro-brasileira e Africana. Brasília: MEC, 2004. Disponível em: $\leq$ http://portal.inep.gov.br/informacao-da-publicacao/-/asset publisher/6JYIsGMAMkW1/document/id/488171>. Acesso em: 14 abr. 2017.

BRASIL. Lei no 11.645. Altera a Lei no 9.394, de 20 de dezembro de 1996, modificada pela Lei $\mathrm{n}^{\circ} 10.639$, de 9 de janeiro de 2003, que estabelece as diretrizes e bases da educaçáo nacional, para incluir no currículo oficial da rede de ensino a obrigatoriedade da temática "História e Cultura Afro-Brasileira e Indígena”. Diário Oficial da República Federativa do Brasil, Brasília, 2008.

COMISIÓN ECONÓMICA PARA AMÉRICA LATINA Y EL CARIBE (CEPAL). Boletín de la infancia y adolescencia sobre el avance de los objetivos del desarrollo del milenio, Santiago. Desafíos, n. 21, p. 1-32, 2018.

CORTÉS, A.R.; APODACA, E.G. El carácter interactoral en la Educación Superior con enfoque intercultural en México. Revista Liminar, México, v. 14, n. 1, p. 73-91, 2016.

ESCOBAR, A. America Latina en una encrucijada: ¿̨modernizaciones alternativas, posliberalismo o posdesarrolo? In: QUINTERO, P. Crisis Civilizatoria, Desarrollo y Buen Vivir. Buenos Aires: Del Signo, 2014. p. 59-106.

FREIRE, J.R.B. A demarcação das línguas indígenas no Brasil. In: CARNEIRO DA CUNHA, M.; CESARINO, P. de N. (orgs.). Políticas culturais e povos indígenas. São Paulo: Cultura Acadêmica, 2014. p. 363-389.

FREIRE, J.R.B. A representação da escola em um mito indígena. TEIAS, Rio de Janeiro, v. 2, n. 3, p. 1-11, 2001.

FREIRE, J.R.B.; MALHEIROS, M.F. Aldeamentos Indígenas do Rio de Janeiro. Rio de Janeiro: EdUerj, 2009.

GRUPIONI, L.D. Quando a Antropologia se defronta com a Educação: formação de professores índios no Brasil. Revista Pró-Posiçôes, São Paulo, v. 24, n. 2, p. 69-80, 2013. http://dx.doi.org/10.1590/S0103-73072013000200006 
MACEDO, E. Base nacional curricular comum: a falsa oposição entre conhecimento para fazer algo e conhecimento em si. Educação em Revista, Belo Horizonte, v. 32, n. 2, p. 45-68, 2016. http://dx.doi.org/10.1590/0102$\underline{4698153052}$

MELIÀ, B. Passado, presente y futuro de la lengua guaraní. Assunção: CEADUC/ISEHF, 2010.

MUNOZZ, H. Reflexividad sociolingüistica de hablantes de lenguas indigenas: concepciones y cambio sociocultural. México: Metropolitana, 2010.

PEREIRA, F.B.; OLIVEIRA, I.B. Ponderaçóes ao Currículo Mínimo da Rede Estadual do Rio de Janeiro: uma contribuição ao debate em torno da Base Comum Nacional. Revista e-Curriculum, São Paulo, v. 12, n. 3, p. 1669-1692, 2014.

ROCKWELL, E. Conversaciones en torno a la educación con pueblos indígenas/migrantes. In: NOVARO, G.; PADAWER, A.; HECHT, A. (orgs.). Educación, Pueblos Indigenas y Migrantes: reflexiones desde México, Brasil, Bolivia, Argentina y Espańa. Buenos Aires: Biblos, 2015.

Recebido em 6 de fevereiro de 2019.

Aprovado em 9 de setembro de 2019. 